\title{
REPAIR OF RUPTURES OF THE ROTATOR CUFF OF THE SHOULDER
}

\section{With a Note on Advancement of the Supraspinatus Muscle}

\author{
J. Debeyre, D. Patte and E. Elmelik, Paris, France
}

Although ruptures of the rotator cuff of the shoulder have long been recognised as a cause of pain and disability, they have always been a source of disappointment to surgeons because of the difficulties of diagnosis and of surgical treatment. Rupture from such injuries as dislocation or contusion of the shoulder, that cause immediate pain and stiffness, are easily recognised, but at other times the symptoms are insidious and first present as a loss of power when the arm is abducted and laterally rotated in simple everyday actions such as doing the hair.

The diagnosis can be confirmed easily by arthrography, which should be done whenever the clinical examination arouses suspicion of a rupture. Gas (Fig. 1) or a radio-opaque liquid (Fig. 2) can be used; entry of either into the subacromial bursa confirms the rupture.

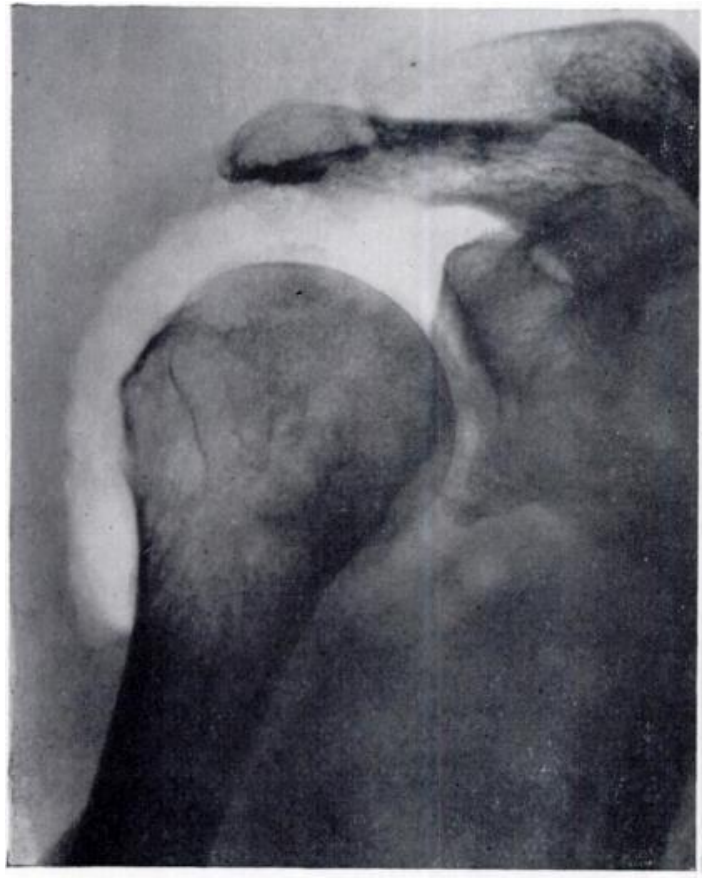

FiG. 1

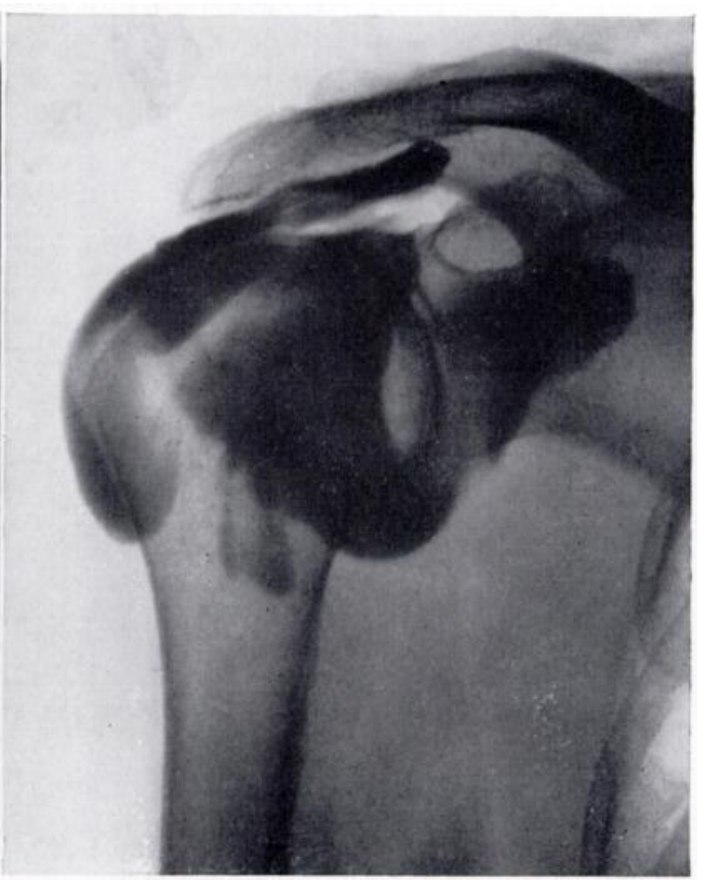

FIG. 2

Figure 1-Air arthrograph in a patient of 75 years with a rupture of the cuff. The intra-articular air has penetrated into the bursa which it fills. The subacromial space is a single empty synovial cavity. There has been a complete detachment of the whole of the cuff. This is often seen in old people. Figure 2-Arthrograph with opaque fluid in a patient of 53 years with a ruptured cuff. The opaque fluid has entered the subacromial bursa, but only to a small extent. There is a rupture of the anterior border of the supraspinatus-which occurred at the time of a dislocation.

Arthrography is essential before operation; in one of our patients it was omitted because of the typical clinical findings, and the rotator cuff was found to be intact.

Arthrography is reliable. Only three explorations showed no rupture even though arthrography suggested it. Two of these shoulders had a long-standing disability and were operated upon through the delto-pectoral route, which gives an exposure inadequate to 
exclude a rupture with certainty. The third without doubt had an intact cuff but, through faulty technique, both the joint and the subacromial bursa had been injected. A later arthrograph confirmed that there was no rupture. On the other hand, in one shoulder a small fissure on the inferior surface of the supraspinatus tendon was located after arthrography; it would not have been recognised by a superficial general exploration (Fig. 3).

Surgical treatment of rotator cuff tears raises two problems: first, the technique of the repair, for which a new method is offered here, and second, the correct indications for operation. The latter can only be decided by a comparison of the results in patients who have been operated on and those who have not.

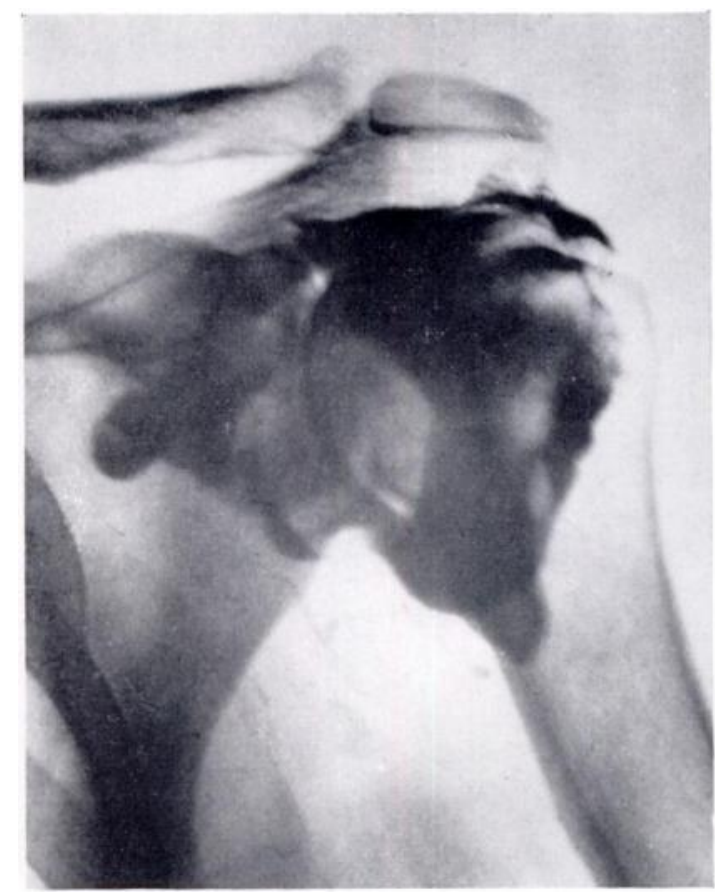

FIG. 3

Arthrograph in a patient of 56 years who had severe pain and loss of power; there is a partial rupture of the supraspinatus tendon. indicated by the fact that there is no filling of the subacromial bursa, but only an additional image superimposed on the superior part of the joint cavity. This is caused by an incomplete rupture of the inferior wall of the cuff.

\section{TECHNIQUE OF OPERATION}

The classical approaches to the shoulder obtain insufficient access. The delto-pectoral incision gives only a restricted view of the region of the greater tuberosity obscured by the acromion process, and provides access only to the humeral insertions of the cuff. The subacromial superior approach damages the insertion of the middle part of the deltoid muscle which is so functionally important to the shoulder. Suture of the ruptured cuff is often impossible because of its extent.

Ruptures of the cuff are either limited to the supraspinatus or extend to the other parts. The initial gap may be wide, and it always increases considerably in the course of time from muscle retraction. Because exploration is usually delayed for some months it is often impossible to close this gap and to reinsert the tendon without excessive tension. From 1951 to 1959 we 
explored seventeen shoulders (Table I). Twice the tear could not be found, probably because of limited access; in eight reinsertion proved impossible, despite good access, because of the extent of the gap; and in only seven was the operation done soon enough-between one and four months-to allow a satisfactory reinsertion to be effected, with good functional results in five of the seven shoulders.

Since 1960 a new technique has been used with a postero-superior approach from above the spine of the scapula and osteotomy of the acromion. The whole supraspinatus muscle from origin to insertion can be seen, and the whole shoulder from the tuberosities to the insertion of the subscapularis and the teres minor can be explored. When necessary the whole of the supraspinatus muscle is elevated from its fossa; the muscle can then be

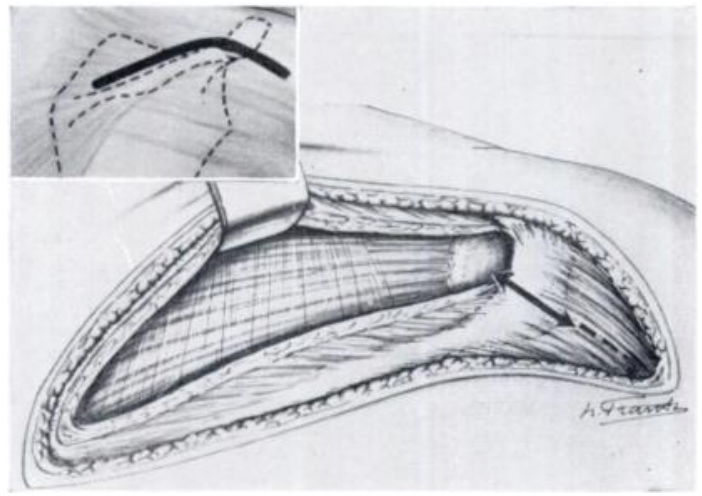

FIG. 4

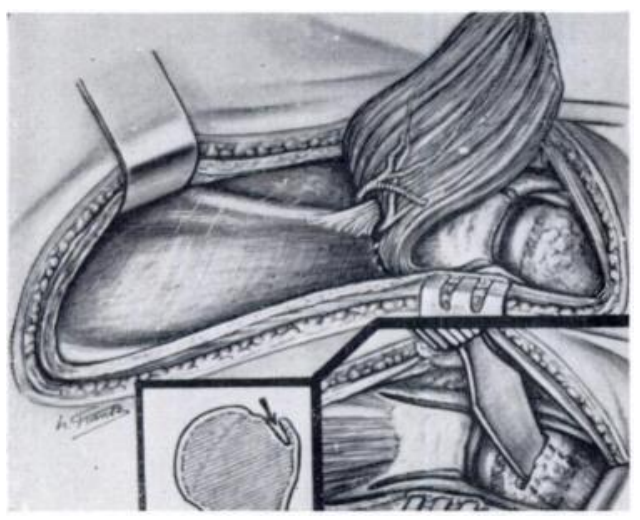

FIG. 6

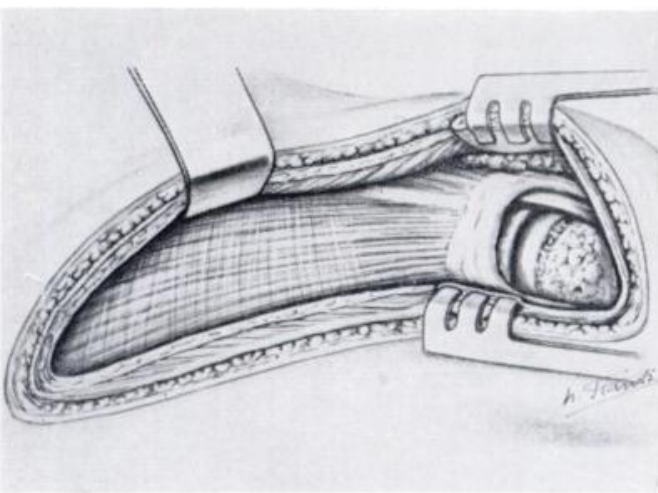

Fig. 5

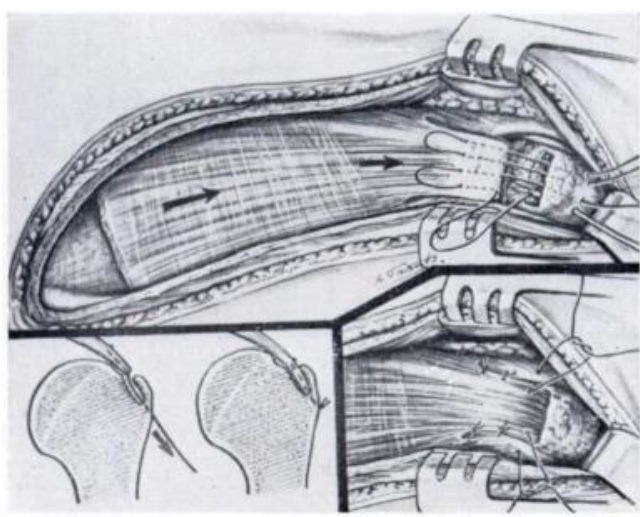

FIG. 7

Stages of the operation.

advanced laterally, permitting closure of a wide gap. This technique is analogous to advancement of the flexors of the forearm in Volkmann's contracture and of the quadriceps for stiffness of the knee joint.

The patient lies prone with the shoulder supported so that the arm can be freely manipulated during the operation. The incision is made a finger's breadth above the superior margin of the spine of the scapula; it curves backwards over the acromion and extends two fingers' breadth beyond its outer margin (Fig. 4). The trapezius muscle is divided one centimetre short of its scapular insertion. An osteotomy of the acromion is done, transversely and obliquely outwards and backwards, leaving the anterior segment connected to the clavicle by the acromio-clavicular joint and the posterior segment continuous with the spine of the scapula. The upper fibres of the deltoid are split downwards from their insertion into the 
acromion, the circumflex nerve being avoided. A self-retaining retractor is inserted to keep the osteotomy of the acromion widely open. The coraco-acromial ligament is divided and the subacromial bursa is opened. The humeral tuberosities are found uncovered to a degree which depends on the extent of the rupture (Fig. 5).

When the elasticity of the supraspinatus tendon allows closure of a small tear it is sufficient to attach the tendon with two U-shaped stitches through the bone and to join it by a few stitches to the anterior and posterior limbs of the cuff. On the other hand, if the gap is large, with widely retracted edges, the supraspinatus muscle is elevated from its fossa with care to preserve the nerve and blood supply (Fig. 6). Fortunately the anatomy of the region permits this manoeuvre. In this way the proximal end of the tendon can be reattached, even in a long-standing case (Fig. 7). Closure is simple. The trapezius muscle is sutured

TABLE I

Comparison of the Results With Different Surgical Approaches to the Shoulder for Rotator Cuff Tears

\begin{tabular}{|c|c|c|}
\hline \multirow[b]{2}{*}{ Approach } & \multicolumn{2}{|c|}{ Number of operations } \\
\hline & $\begin{array}{l}\text { Delto-pectoral or } \\
\text { subacromial } \\
1951-1959\end{array}$ & $\begin{array}{c}\text { Transacromial } \\
1960-1962\end{array}$ \\
\hline No tear found & 2 & 2 \\
\hline Reinsertion impossible & 8 & - \\
\hline Reinsertion possible & 7 & 44 \\
\hline Total operations & 17 & 46 \\
\hline Total satisfactory & 5 & 41 \\
\hline
\end{tabular}

and the fibres of the deltoid are approximated. The plane of the osteotomy of the aciomion is at right angles to the line of pull of these two muscles and formal osteosynthesis is not needed. A suction drain is placed in the supraspinatus fossa, where bleeding is always rather profuse. A thoraco-brachial plaster spica, with the arm abducted, is applied and retained for four to six weeks until the patient has recovered good power in the deltoid. Re-education is begun in this position and kept up vigorously for three or four months.

\section{RESULTS}

We have used this exposure on forty-eight shoulders and have been able to repair all the forty-six ruptures of the cuff that were discovered; twice no rupture was found. In twentythree shoulders, that is in 50 per cent, advancement of the supraspinatus was necessary to close the gap. Two patients have not been followed up, so that for the purpose of analysis of the results, forty-four patients can be considered (Table I). Of the forty-one patients with satisfactory results eighteen were excellent, that is, with almost complete freedom from pain from the time of operation and complete recovery of power and range of movement except for some 20 or 30 degrees of outward rotation; eleven had good results and twelve were improved. In the latter, despite marked reduction of pain, recovery of movement was incomplete, though the range of abduction was over 100 degrees; nine of these twelve patients had resumed work and were satisfied. Three patients were failures; the functional state was unchanged and they were dissatisfied. Most good results could be recognised from about the third month after operation but with re-education a further proportion of patients came into the good category in the ensuing three months. The quality of this treatment and the patient's co-operation were of the greatest importance.

VOL. 47 B, NO. 1, FEBRUARY 1965 
Mobility-The improvement of abduction is shown in Table II. Before operation only four patients had a normal range of abduction, but with much diminished power and poor control at the extremes. After operation. however, twenty-three patients had ranges of abduction from 160 to 180 degrees. No patient had mobility reduced by the operation. In eight patients the range of abduction was not increased; of these, three were considered to be failures, but the other five had a normal range of abduction before and after the operation and all had good results. In six patients the improvement was slight, for example, from 40 to 60 degrees of abduction. In the remaining thirty patients the improvement was considerable.

Some limitation of rotation frequently persisted even with the best results. Lateral rotation with the arm abducted 90 degrees was often improved, which explains why some

TABLE II

Range of Abduction Before and After Operation

\begin{tabular}{|c|c|c|}
\hline \multirow{2}{*}{ Range in degrees } & \multicolumn{2}{|c|}{ Number of patients } \\
\hline & Before operation & After operation \\
\hline Normal & 4 & 23 \\
\hline $120-160$ & 3 & 11 \\
\hline $90-120$ & 6 & 6 \\
\hline $60-90$ & 12 & 2 \\
\hline $0-60$ & 19 & 2 \\
\hline Total & 44 & 44 \\
\hline
\end{tabular}

TABLE III

Pain Before and After Operation

\begin{tabular}{|c|c|c|}
\hline \multirow{2}{*}{ Amount of pain } & \multicolumn{2}{|c|}{ Number of patients } \\
\hline & Before operation & After operation \\
\hline None . & 2 & 29 \\
\hline Some . & 9 & 11 \\
\hline Continual & 27 & 4 \\
\hline Intolerable . & 6 & - \\
\hline Total . & 44 & 44 \\
\hline
\end{tabular}

patients with apparently absent lateral rotation nevertheless regained full abduction. The limitation of lateral rotation stayed practically constant when there was a complete rupture which involved the infraspinatus tendon, and this suggests that it might be helpful to reinsert that muscle also. Two patients have, in fact, had combined reinsertion of both muscles; both had good results but only one recovered a near-normal range of lateral rotation.

Pain-The relief of the pain is usually spectacular (Table III). Twenty-nine of the forty-four patients had complete freedom from pain, ten had less and only five were not improved. The patients attached more importance to the relief of pain than to improved movement. For this reason the subjective result, so important in an operation to improve function, was sometimes found to be better than the objective result. Out of twenty-five patients very satisfied with the operation there were four who had, objectively, very poor results. 
That all the ruptures of the cuff that were discovered could be closed was because of the excellent exposure. When the seventeen patients operated on from 1951 to 1959 are compared with the forty-eight operated on since then (Table I) there is seen to be a marked improvement in the number of good results (from 29 per cent to 63 per cent), even though the recent results have been assessed more critically. Over the last two years three times as many ruptures have been operated upon as in the last ten years, because previously no attempt was made to repair ruptures more than four months old.

\section{INDICATIONS FOR OPERATION}

It is only justifiable to recommend operation when the diagnosis has been confirmed by arthrography, because a diagnosis on clinical evidence only may be incorrect. The age of the patient matters little. Most of our patients were between fifty and seventy but two were even older. The younger the patient the easier the rehabilitation after operation.

The etiology of the rupture, whether from injury or from degenerative changes-when it is possible to differentiate-makes some difference. Of twenty patients with degenerative tendinitis seventeen had satisfactory results ( 85 per cent); of twenty-four patients with rupture after injury with no preceding periarthritis, twelve had satisfactory results ( 50 per cent). The reason for this is not clear. The extent and duration of the lesion were important (Table IV).

TABLE IV

Results Related to the Extent of the Lesion and Type of Operation

\begin{tabular}{|c|c|c|c|c|c|c|c|}
\hline \multirow{3}{*}{ Lesion and repair } & \multicolumn{7}{|c|}{ Number of patients } \\
\hline & \multirow{2}{*}{$\begin{array}{l}\text { Total } \\
\text { in } \\
\text { group }\end{array}$} & \multicolumn{4}{|c|}{ Type of result } & \multicolumn{2}{|c|}{ Satisfactory results } \\
\hline & & Excellent & Good & Improved & Failure & Total & Per cent \\
\hline $\begin{array}{l}\text { Recent isolated rupture of the supraspinatus } \\
\text { with simple suture. }\end{array}$ & 21 & 10 & 6 & 4 & 1 & 16 & 76 \\
\hline $\begin{array}{l}\text { Rupture of the supraspinatus with suture } \\
\text { after advancement of the muscle }\end{array}$ & 12 & 4 & 3 & 4 & 1 & 7 & 58 \\
\hline $\begin{array}{l}\text { Extensive rupture of the cuff with suture } \\
\text { after advancement of the muscle }\end{array}$ & 11 & 4 & 2 & 4 & 1 & 6 & 54 \\
\hline
\end{tabular}

Twenty-one ruptures of the supraspinatus alone were treated by simple suture, there being limited gaps with little retraction, which are evidence of recent lesions. Of these, ten had excellent results, six had good results, four were improved and one was a failure. Twelve ruptures treated by advancement of the supraspinatus muscle produced seven satisfactory results (58 per cent), four were improved and one was a failure. Eleven extensive ruptures, treated by repair of the supraspinatus only after advancement of the muscle, gave quite good results, four being excellent, four improved and one a failure.

Of two patients with combined supraspinatus and infraspinatus tears, the one which was treated by advancement of the supraspinatus had an excellent result. The other, treated by advancement of both supraspinatus and infraspinatus, had an improvement in abduction from 30 to 140 degrees but has no outward rotation and no relief of pain.

Obviously advancement of the supraspinatus does not give the best functional improvement. Only thirteen patients have abduction to 140 degrees or more with freedom from pain, but nine have kept or regained normal outward rotation. This, and the absence of any sign of nerve degeneration by electromyography, indicates that the transposed muscle maintains its ability to contract. The operation does not, therefore, merely supply padding to the subacromial 
region. The sooner the operation is done the better the result; also a small rupture requiring simple suture gives a better result.

Unfortunately the long term effects of an untreated rupture are not yet known. After an injury with a rupture confirmed by arthrography the shoulder often regains satisfactory function with rehabilitation only. In elderly patients one shoulder in four has a degenerative rupture of the cuff but with almost normal, painless movement, and many of these, discovered by arthrography, have only slight functional disability, will improve with physiotherapy and do not need operative treatment. Because half of the patients who have sustained a rupture of the cuff obtain a good functional result spontaneously, the indication for operation depends upon the diagnosis being confirmed by arthrography and the failure of four to six months physiotherapy to cause improvement. Operation is not contra-indicated for reasons of local pathology, because the continuity of the cuff can always be restored with this new surgical technique.

\section{SUMMARY}

1. The results of operation in sixty-three patients with rupture of the rotator cuff of the shoulder have been reviewed.

2. In seventeen patients the classical delto-pectoral route was found to give poor access and mediocre results.

3. In forty-six patients a superior approach along the supraspinatus fossa and through the divided acromion process was found to give excellent access and to permit lateral advancement of the supraspinatus muscle in order to enable wide gaps to be closed. With this improved surgical access the proportion of good results has been doubled.

4. It is suggested that when a case of rupture of the cuff, confirmed by arthrography, fails to respond to physiotherapy, operative repair should be undertaken.

Most of the patients have been referred to us by Professor S. de Sèze, to whom we are most grateful. 